\title{
Give me an Easy Topic, Please: My Experience of Supervising Theses
}

Sajan Kumar Karn

\begin{abstract}
Thesis writing is demanding in that it requires a great deal of time, patience, study, creativity, writing proficiency and also critical and analytical expertise on the part of researchers. Unfortunately, many of the beginners do not seem to understand the gravity of such a high level academic feat and consequently pose a lot of problems for thesis supervisors, guidance committee, university department, etc. This paper endeavors to scrutinize students' misconceptions and negligence against depth and requisites of the thesis writing. Besides this, it also tries to specify the expected responsibilities of supervisors and researchers. This largely draws on my experience and inferences obtained while supervising M. Ed. (English) theses, unstructured interview (conversation) with the students/researchers, a close examination of thesis drafts, and interactions with colleagues (thesis supervisors).
\end{abstract}

Key words: Research, plagiarism,research problem, thesis writing

\section{Thesis writing: misconceptions vis-à-vis realities}

"Give me an easy topic, please". This is the phrase most of the thesis writers (M.Ed. English students) utter to me when they wish to undertake thesis writing under my guidance. The request puzzles me and I stay tight-lipped for a while as I do not know what to say and how to say. This generates a number of questions in my mind: Am I the person supposed to provide them topics? Are there topics called easy and difficult? Do I have a stock of thesis topics? Am I supposed to play an imposing role of asking pupils to write thesis on topics of my interest/ choice? What is my responsibility as a supervisor? What roles do they have as researchers? and so on. However, I become calm in a few moments as I come to realize that this is not my personal story but a common saga of thesis supervisors. In this connection, I would like to re-share a lighthearted discourse that a senior faculty in the Department of
English Education, University Campus, Tribhuvan University (TU) shared with me three years back. The conversation between him and a researcher progressed in this way:

Researcher: Give me an EASY topic, please.

Supervisor: (ironically) I am so sorry, I had brought one EASY topic but gave it to another student.

Researcher: Sir, you know I am pretty occupied. So, do me a favor.

Supervisor: Alright, I will bring another EASY topic for you tomorrow.

Researcher: There is going to be a vacancy in a $10+2$ in my village. If I were able to finish earlier

The talk betrays that the student seems to have conceived that it is the supervisor who is supposed to assign topics and they can be easy or difficult. He is also short of time. He wants to accomplish it as soon as possible for he does not want to miss the opportunity of getting an employment in the school 
of his village. This seems to be a general tendency amongst students as virtually all the students are found to make a request for easy topic as they begin writing thesis.

Likewise, let us look at another piece of conversation (with me) that reflects the students' (mis-) conception about thesis writing:

Researcher: I wanna do thesis, sir.

Supervisor: Good but you know, thesis is extremely demanding.

Researcher: Please help me.

Supervisor: I am here to help but you have to spend a lot of time, efforts, money.....

Researcher: You know, my schedule is too hectic but I will spare some time in the evening.

Supervisor: uhhh....

Researcher: Sir, I will come to you, please make me write one-two pages(dictate) every day so that I can finish within a month.

I am using a pseudo name of the researcher.

Again this conversation shows the researcher is willing to do thesis but he does not have enough time. He has not started yet but is worried about completing it at the earliest. Another big misunderstanding he has is that he thinks it is some sort of dictation that a supervisor is supposed to do in order to produce a thesis.

Let us now look at another piece of conversation that occurred some days before the viva-voce of a thesis.

Researcher: Sir, I have come to make a request.

Supervisor: well, what's that?

Researcher: My thesis viva is the day after tomorrow.

Supervisor: I see. That's okay. Prepare well and best of luck for that.

Researcher: But there is a problem. .....I need forty five (90\%) in thesis to have second division. Please, this is related to my career and life.

Supervisor: So what? What do you want to say? What can I do? (expressing anger)

This is again the dialogue between me and my student (researcher) before the viva voce.
The above talk now infers that student has opted for thesis as he considers thesis to be mark-fetching and he thinks by requesting a member of thesis evaluation committee, he can obtain the marks he needs to have desired division.

Likewise, let us see another conversation that points out another misunderstanding that students bear about thesis writing.

Researcher: Sir, please speed up my thesis.

Supervisor: Ramesh ji, you are supposed to do that, not me.

Researcher: I submitted yesterday. Please, arrange viva as soon as possible.

Supervisor: Yes, you did it but look...there are a lot of things to be corrected. Look at the grammatical errors you have made. This is a duplicationplagiarism, Rameshji. you have copied pages from others' theses. You must acknowledge whatever you borrow. You are supposed to follow APA style of referencing, there is no consistency in margin and font size.... It is not double spaced. Theoretical background is also not enough either. Review of the related literature has to be in chronological order.

Researcher's friend (Union leader): Try to understand, sir. Please do not give unnecessary trouble to students, at least my students. Ramesh belongs to my group.

Supervisor: Thakur ji, You must understand: how sensitive work thesis is. How can I recommend the thesis that is so carelessly prepared? It is linked with my prestige, and also Department's reputation. I think he needs to spend at least one more month on it.

Researcher's friend (Union leader):.

This debate happened between me and researcher (and his friend) last year and created a lot of troubles. Again the conversation uses pseudo-names.

For this student, thesis writing is merely a ritual: he seems to have borne that thesis can be submitted in any manner. He does not seem to pay any heed that there is a proper style of writing and the theses should adhere to the standards of the Department. Besides, he has brought union leader for help. 
These poor states of affair can be generalized as most of my colleagues working in the same Department of different campuses of TU have expressed by and large similar experiences.

My experience of supervising M.Ed. theses for about half a decade has unveiled that the students/ researchers seem to have developed numerous misconceptions about thesis writing. One may argue that it might have been happening owing to lack of ample orientation and ignorance about the rigor of research. I would refute it in that even after adequate guidance, the wrongs get repeated.

Some of the misconceptions have been enumerated and explained below in comparison to the requisites the researchers are supposed to abide by:

Thesis is merely a means of acquiring a qualification

There is no denying that thesis writing is a part of academic qualification. Nevertheless, most of the M. Ed. students (researchers) seem to overlook the spirit of thesis writing (a research work) and simply concentrate on how to obtain the degree at the earliest. "There is often a natural tendency to be thinking continually about the final qualification and to treat the thesis writing simply as a means to that end" (Oliver, 2004:4). This underrates the gravity of thesis writing which is a form of exploration. Unlike personal essays that express personal thoughts, feelings and opinions, thesis requires one to go beyond personal knowledge and experience. One undertakes research when they wish to explore an idea, probe an issue, solve a problem, or make an argument that compels them to turn to outside help (Gibaldi, 2004:3). Stressing its creative dimension, again Oliver maintains "Thesis writing is not merely an instrumental activity but an opportunity to express understandings about the world in a fresh and novel way" (ibid.). Consequently, it demands a great deal on the part of the writer. A researcher is supposed to be aware of standards that the department has set. Therefore, considering thesis writing merely from instrumental perspective makes it less investigative and undervalues its magnitude as well.

Certain types/areas of research are easy and others are relatively more difficult
I wonder if ease or difficulty lies in the area or type of research one is going to carry out. The fact is that thesis is one of the most demanding scholarlry tasks. Best and Kahn opine "A thesis is a piece of formal academic writing which reports on a research study. The research worker should be a scholarly, imaginative person of the highest integrity, who is willing to spend long hours painstakingly seeking the truth" (2002:22). A researcher should have ample time in order to study related materials, prepare tools to collect data, analyze and interpret them, prepare a draft, edit and re-edit it, proof-read it and so on. $\mathrm{He} /$ she needs to have creative and inquisitive brain to contribute to professional enhancement with the research. All areas or topics are of equal intricacies and therefore, demand equally. It is another matter that those who have gone through the research literature and have developed skills required, find the task relatively easier.

\section{Thesis is (not) mark-fetching}

Rumor has it that thesis fetches high scores. Many of the students seem to opt for thesis as they have developed a pseudo-impression that thesis writing is comparatively more mark-fetching in than the paper namely, Discourse Analysis (an elective paper which can be opted for instead of thesis writing). I have received a dozen of pleadings and pressures to award or persuade the concerned for lofty marks as it is a practical kind of thing. This is a hundred percent wrong concept. If thesis writing is inspired by this default impression, this diverts the primary focus of research which is the contribution of knowledge and solution of certain professional problems. We cannot expect such theses to contribute anything worthwhile. Score is something that depends on the level of study and performance. If one studies hard and is able to present/produce his/her work accordingly, any subject/paper fetches high marks. If a student completes the thesis within the stipulated time, produces linguistically excellent work and most importantly his or her work carries something original and meaningful, no doubt he/she secures high marks. However, a research work (thesis writing) must not be guided by such instrumentalities. 


\section{Writing a thesis is an act of reproducing and compiling texts from various sources}

For many of the students, thesis writing is similar to the compilation of stuffs from different sources. A large number of the theses are found to have the ideas, sentences and paragraphs borrowed from different scholars and previous research works without acknowledgements. Many of them seem to be unaware of the fact that when they borrow contents from other sources they have to cite them properly. However, many do it deliberately as they are pretty busy and therefore, cannot spare time required. Experience shows that writing thesis has become more a mechanical work than creative one. Students are found to exert little effort on contemplating and studying about theoretical background, methodology and methods of analysis and interpretation. Majority of them just cascade most of the contents and strategies from previously carried out theses. This is plagiarism. "Using another person's ideas, information or expressions without acknowledging that person's work constitutes intellectual theft. Passing off another person's ideas information or expressions as your own to get a better grade or gain some other advantage constitute fraud"(Gibaldi, 2004:66).

\section{Thesis supervisor is like a narrator}

Some of the students also seem to have formed a belief that it is the supervisor who is supposed make them write thesis. In other words, they expect some sort of dictation from supervisors. Many a time, I have come across students asking me to dictate thesis either partially or completely. I remember a student turned leader requesting me repeatedly to write a thesis for him. Later, I came to know that he got a professional thesis writer who did all work for him. I wonder if my job as a supervisor is that of a narrator. The supervisor's role is clearly not one of doing the work for the students i.e. writing thesis or narrating it partially or completely, but of providing advice and support in order to help researchers produce the best theses which they are capable of.

It is supervisor who is responsible to edit, re-edit and proof-read the drafts of thesis
It is the job of teacher/supervisor to edit and proofread the thesis, most of the students assume. They submit their first draft without even giving a first reading. They just print the first draft and bring it straight to the supervisors as if they (supervisors) were editors. Now supervisor is expected not only to correct grammatical errors but also to show where they should use capital letters and small letters, which quotations to indent and which not to, what font of what size to use, how to cite, how to reference, how much to leave for margins, how to write headings and subheadings, in fact, everything. This over-expectation seems to have made thesis supervising more mechanical and less creative.

\section{Thesis writing is a formality}

Students do not seem to understand that a thesis is a form of communication. Instead they seem to consider thesis writing to be a ritualistic activity. A thesis finally is the property of Department of a University or Campus. It is stored in a library where it is uploaded on a website. Now the thesis is subject to be read by future and also overseas students. Therefore, if thesis is not well written, it damages the long earned reputation of the supervisor, Department, Campus and also University. A thesis writer has to consider this while doing the task. Editing and proof-reading has to be done meticulously by researchers themselves to avoid lapses so that the dignity of the supervisor, Department etc. is upheld.

\section{Thesis writing is ornamental}

Often students are found using ornamental language in their thesis. They do not seem to distinguish between academic writing and creative one. Unlike creative writing which is subjective and imaginative, academic writing does not give the same freedom of expression. A researcher "must inform directly, objectively with clear and concise language" (Coppedge, 2009:21). A scientific writing does not accept ornamental language. Day (1995) states "The flowery literary embellishments-the metaphors, the similes, the idiomatic expressions-are very likely to cause confusion and should seldom be used in writing research papers. The dictum that needs to 
be kept in mind is "The best English is that which gives the sense in fewest short words" (p. 2).

\section{Supervisors delay the process of thesis writing}

Students seem to have misconceived that supervisors intentionally delay the process of thesis writing. Often the students allege their teachers for not speeding the process of thesis completion. They frequently accuse the teachers for not providing enough time. Likewise, they are also blamed for not managing the viva promptly. They do not seem to understand the fact that things take time. Thesis is a sensitive work and therefore haste makes waste. "Research is characterized by patient and unhurried activity. It is rarely spectacular, and the researchers must expect disappointment and discouragement as they pursue the answers to difficult questions" (Best and Kahn, 2004:22). Once the student has submitted thesis to the supervisor, he/she has to find time to go through it as he/she has a number of other responsibilities besides guiding of the thesis. Again going between the lines of the draft and examining every bit thoroughly require time. Sometimes even after the submission of thesis, administrative matters take time and theses are sent to the subject committee later than they should be. On the part of students, M.Ed. thesis requires one to spend 3 months of minimum time. However, this may not be enough for data collection and analysis and may take additional time, say some six months or even longer. I have come across some students wanting to submit their thesis only after two months of the viva of the proposal, which implies that students are not aware of time schedule and also the haste for the final qualification, which might damage the quality of thesis. However, it is seen that a few good students are able to accomplish thesis within the stipulated time.

\section{A thesis supervisor is a topic-provider}

My experience has shown that even after a number of efforts on our part (supervisors) to make the researchers understand that selection of topic is their own job; students have virtually depended on supervisors to assign them topics. The fact is that supervisor is not supposed to provide topics to the researchers; it is the task of researchers to pick up topics that suit and interest them. Nevertheless, selection of topic has to be done with the consultation and approval of the supervisor.

\section{How to pick up a thesis topic}

Selecting a topic is of course a difficult decision, but if students follow their instincts, they will find their way to an appropriate and meaningful topic. I think if students follow the below-given tips, their job of picking a topic becomes easier.

Choose a topic of your interest: This is the most democratic procedure for the selection of topic. Instead of being imposed and pressurized by the supervisor or others, if students pick of the topic that is interesting to him, the research will be more fruitful. For instance, if a student finds the area of Code-mixing interesting, he/she should not venture for Contrastive Analysis (CA) or Error Analysis (EA) upon the recommendation of a supervisor. If $\mathrm{CA}$ or EA is chosen, he/she will not be able to exert that much interest in it and consequently the product will not be that significant.

Pick up a topic that has pedagogical implications: The researches of the Department of English Education intend to seek pedagogical applications. As the M.Ed. graduates of today are the teacher trainers/educators of tomorrow, they will be dealing with the problems of second language acquisition, the role of first language, error analysis, contrastive analysis, language testing, course designing, effectiveness of a particular technique in teaching, textbook analysis, evaluation, motivation, materials etc. In other words, whatever topics are picked up they are supposed to have some pedagogical implications (Bhattarai, 2005:164). I remember a student bringing a topic- $A$ Descriptive Study of the Bhojpuri Language. The topic in no way is linked to ELT and does not have any pedagogical implications for ELT either.

Choose a distinctive topic: Overdone areas should not be picked as they contribute a little to the body of knowledge. This is also to avoid duplication that is likely to take place. Researchers should think 
of contributing significantly to the concerned profession. They should be creative and choose an idea that stands out from the pack as original and innovative.

If students are asked to select topics on their own, they are found to select those topics that have been overdone so that they could just transfer most of the contents -theoretical background, objectives, significance, methodology, etc. For instance, one student said that he wanted to do thesis on "Effectiveness of Communicative Strategies in Teaching Stories" because there was already a thesis on "Effectiveness of Communicative Strategies in Teaching Poetry".

Pick up a topic offuture profit: A topic if chosen from future perspective will be more beneficial. Before selecting a topic, the students need to contemplate if the topic will have any future significance in their career. For instance, a student aiming to be a teacher should pick up the topic that can enhance their further pedagogical career. However, if a student aims to be a course framer or an administrator or a researcher, he/she should concentrate on the other related topics.

Avoid controversial topic: Controversial topics should be avoided as far as possible. However, if one chooses a controversial topic, they need to think carefully about whether it might restrict their employment, tenure, or publishing opportunities.

Consult supervisor: Whatever topic a researcher wants to write thesis on, he/she should consult the supervisor for final consent. It is because there is no doubt to the fact that a supervisor knows more about the efficacy of such a work. He also knows whether it is going to be feasible or not.

Go through the literature: One of the most useful exercises when one is planning to write a thesis is to go through the list of theses in the department. Quite apart from issues about content and subject matter, it is often helpful to see the way in which other researchers have approached both the structuring and writing of their theses.

Pick a manageable topic: I remember one of my students had written a proposal entitled "ELT Situation of Nepal". Is not it a too giant project for a bigginer (Master's degree students)? Surveying ELT situation will take a long time - a couple of years or even more. Besides, it does not seem possible for a single researcher to dare for such a stupendous task.

\section{Responsibilities of the thesis supervisor}

Most of the researchers seem to depend on supervisors for a large number of work. A thesis supervisor does assume a number of responsibilities. However, his role seems to be more of an advisor than of a doer. The following are the assumed responsibilities of the thesis supervisor:

To provide essential suggestions from the beginning through the completion of thesis writing

To recommend materials (theses, journals, books etc.) required to be consulted

To provide suggestions on formulation of objectives, development of data collection tools and tips for analysis techniques etc.

To examine theses on the matters of structure, referencing (citing) style, mechanics of writing etc. and to advise students to abide by the standards of Department and University

To recommend proposal and thesis for evaluation if requirements are met.

The above mentioned roles are consultative in nature. Nevertheless, this consultative job requires supervisor to inspect and examine carefully and thoroughly the work of students and help them produce the best they can. After the submission of thesis, the supervisor has to ask himself/herself the following questions before he/she recommends it for evaluation (Oliver, 2004:168).

- Is the abstract clearly written and an accurate précis of the thesis?

- Does the introduction set out the research question clearly?

- Are the aims clearly stated and achievable?

- Is the literature review sufficiently comprehensive for the academic level of the thesis?

- Is the literature reviewed relevant to the 
subject matter of the thesis, and sufficient contemporary?

- Is the research design relevant to the research aims?

- Does the account of methodology demonstrate an adequate appreciation of research methods, relevant to research design and subject to the research?

- Is the data sufficiently and appropriately analyzed?

- Do the results and conclusions derive logically from the analysis?

- Are the ethical issues inherent in the study discussed adequately?

- Is the linguistic style of the thesis appropriate to the academic level?

\section{Responsibilities of the student/researcher}

Thesis writing is essentially students' work. It is them who have to write theses. In order to do so, they have bigger responsibilities to perform. They have:

- To select a topic that is novel and can contribute something original

- To study the related theses, journals, research books etc.

- To write a comprehensive research proposal adhering to the standards of the department and university

- To seek suggestions from the supervisor and other members of the thesis guidance committee on the matters of confusion and difficulties

- To abide by the suggestions given by supervisor

- To prepare tools to gather data

- To analyze the data properly, taking help from guide or others who know

- To produce thesis in accordance with the rules and standards of the department/university

- To maintain accuracy and consistency throughout the thesis.

- To acknowledge properly the sources of materials and ideas borrowed, paraphrased or derived

- $\quad$ To realize that the supervisor has many other duties which may at times delay the student's access to the supervisor

- $\quad$ To edit, re-edit, and proof-read the drafts of thesis meticulously before submission

- To be aware of thesis evaluation criteria

\section{Conclusions}

Thesis writing is considered a collaborative work for it involves researcher, supervisor, thesis guidance committee and many other individuals and organizations. Nonetheless, it is the students/ researchers who have to take the charge of initiating and doing the task. Others are available only if researchers seek their assistance and guidance. It is therefore a misconception on the part of students to expect much from supervisor and others. Overexpectation of students from supervisors has made thesis writing more mechanical and less creative. Likewise, thesis which is a form of exploration and communication demands profoundly on the part of researchers. On the one hand, they have to be innovative and on the other they have to produce the work that adheres rigorously to the standards of the University/Department. Unless the researchers understand the sensitivity and worth of such an academic activity, thesis writing will continue creating problems. Therefore, in order for thesis writing to make sensible expedition of innovation, students/researchers must wipe away the misconceptions discussed above.

Sajan Kumar Karn has been associated with English Language Teaching and linguistics for a decade. He has published a number of articles in various newspapers and journals. To his credit, he has co-authored two titles on Applied Linguistics. He has edited three volumes of ELT Today, Journal of NELTA Birgunj and Contemporary Issues in ELT, a special issue of NELTA Birgunj. He is serving NELTA Birgunj in the capacity of Vice-Chair at present. Currently, he teaches the courses on Applied Linguistics, Phonetics and Phonology, General English, and English Linguistics at TRM Campus Birguni, Tribhuvan University. He has recently attended Study of the United States Institute (SUSI) a six week long program held in the University of Florida, USA. He is more interested in the studies related to critical applied linguistics, language planning, second language learning and World Englishes. 


\section{References}

Best J.W. \& Kahn, J. V. (2004). Research in education ( $7^{\text {th }}$ ed.). New Delhi: Prentice Hall of India.

Bhattarai, G.R. (2005). A thematic analysis of research reports ( $2^{\text {nd }}$ ed.). Kathmandu: Ratna Pustak Bhandar.

Day, R.A.(1996). How to publish a scientific paper ( $4^{\text {th }}$ ed.). Delhi: CUP.

Gibaldi, J. (2003). MLA handbook for writers of research papers ( $6^{\text {th }}$ ed.) New Delhi: Affiliated East-West Press Pvt. Ltd.
Gretchen, C. (2009). Do not forget your readers. Contemporary issues in ELT. Birgunj: NELTA.

Hatch, E. \& Farhady, H. (1982). Research design and statistics for applied linguistics. Rowley, Massachusetts: Newbury House Publishers, Inc.

Kumar, R. (2005). Research methodology (2 ${ }^{\text {nd }}$ ed.). Delhi: Pearson Education Pte. Ltd.

Oliver, P. (2005). Writing your thesis. New Delhi: Vistaar Publications. 